\title{
Molecular analysis of myocilin and optineurin genes in Korean primary glaucoma patients
}

\author{
JOONHONG PARK ${ }^{1,2}$, MYUNGSHIN KIM ${ }^{1,2}$, CHAN KEE PARK $^{3}$, HYOJIN CHAE $^{1,2}$, SEUNGOK LEE $^{1,2}$, \\ YONGGOO $\mathrm{KIM}^{1,2}$, WOORI JANG ${ }^{1,2}$, HYUN YOUNG CHI $^{4}$, HAE-YOUNG LOPILLY PARK ${ }^{3}$ and SHIN HAE PARK ${ }^{3}$ \\ ${ }^{1}$ Department of Laboratory Medicine; ${ }^{2}$ Catholic Genetic Laboratory Center, Seoul St. Mary's Hospital; \\ ${ }^{3}$ Department of Ophthalmology and Visual Science, College of Medicine, The Catholic University of Korea, \\ Seoul 06591; ${ }^{4}$ Department of Laboratory Medicine, Samkwang Medical Laboratories, Seoul 06742, Republic of Korea
}

Received September 20, 2015; Accepted June 27, 2016

DOI: $10.3892 / \mathrm{mmr} .2016 .5557$

\begin{abstract}
To investigate the underlying genetic influences of primary glaucoma in Korea, molecular analysis was performed in 112 sporadic cases, and results compared with healthy controls. The myocilin (MYOC) and optineurin (OPTN) genes were directly sequenced in 112 unrelated patients, including 17 with primary open-angle glaucoma, 19 with juvenile open-angle glaucoma, and 76 with normal tension glaucoma. Healthy unrelated Korean individuals $(n=100)$ were used as the non-selected population control. A total of three $M Y O C$ and four $O P T N$ variants potentially associated with primary glaucoma were identified in 4 and 18 patients, respectively. A novel variant of MYOC, p.Leu255Pro, was predicted to be potentially pathogenic by in silico analysis. Another, p.Thr353Ile, has been previously reported. These two missense variants were detected in patients with a family history of glaucoma. Combined heterozygous variants p.[Thr123=;Ile 288=] were identified in 2 of $112(2 \%)$ patients but not in healthy controls. Among OPTN variants, a novel variant p.Arg271Cys was identified. Homozygous $p$.[Thr34=;Thr34=] (4/112, 4\%), homozygous p.[Met98Lys;Met98Lys] (4/112, 4\%), or combined heterozygous $p .[$ Thr34=;Arg545Gln] $(9 / 112,8 \%)$ was significantly associated with the development of primary glaucoma [odds ratio $(\mathrm{OR})=8.768,95 \%$ confidence interval $(C I)=1.972-38.988$; relative risk $=1.818,95 \% \mathrm{CI}=1.473-2.244$; $\mathrm{P}=0.001]$. The present study provides insight into the genetic
\end{abstract}

Correspondence to: Dr Myungshin Kim, Department of Laboratory Medicine, College of Medicine, The Catholic University of Korea, 222 Banpo-daero, Seocho-gu, Seoul 06591, Republic of Korea

E-mail: microkim@catholic.ac.kr

Dr Chan Kee Park, Department of Ophthalmology and Visual Science, College of Medicine, The Catholic University of Korea, 222 Banpo-daero, Seocho-gu, Seoul 06591, Republic of Korea

E-mail: ckpark@catholic.ac.kr

Key words: primary glaucoma, molecular analysis, myocilin, optineurin, mutation or haplotype variants of $M Y O C$ and $O P T N$ genes contributing to primary glaucoma. Haplotype variants identified in the present study may be regarded as potential contributing factors of primary glaucoma in Korea. Further studies, including those on additional genes, are required to elucidate the underlying pathogenic mechanism using a larger cohort to provide additional statistical power.

\section{Introduction}

Glaucoma is a complex, heterogeneous ocular disorder with multifactorial etiology characterized by structural damage to the optic nerve, visual field defects (1) and commonly relatively high intraocular pressure (IOP) (2). It is a leading cause of irreversible blindness worldwide $(3,4)$ with $\sim 20 \%$ of cases occurring secondary to other ocular or systemic diseases (1). Based on anatomical changes in the anterior chamber angle, primary glaucoma may be classified as primary angle closure glaucoma (PACG) or primary open-angle glaucoma (POAG), which may be further subdivided into juvenile open-angle glaucoma (JOAG) and adult onset POAG $(1,5)$. Glaucoma is a treatable disease if detected early; however, many patients are diagnosed during routine examinations or only following advanced field loss, as glaucoma is typically asymptomatic in the early stages. Therefore, the development of an accurate test for the detection of presymptomatic carriers at risk is important for the management of glaucoma.

A family history of glaucoma is a well-known risk factor. Therefore genetic background is considered important for the development of the disease (6-8). The following genes have been reported to be associated with primary glaucoma: myocilin (MYOC) (9), optineurin (OPTN) (10), WD repeat domain $36(11,12)$, neurotrophin $4(13)$,optic atrophy $1(14,15)$, cytochrome $P 450$ family 1 subfamily $B$ member 1 (16) and latent transforming growth factor $\beta$ (17). To date, mutations in these genes account for only $\sim 5 \%$ of patients with POAG (18), and the influence of mutations in these genes on patients with PACG remain controversial (19). The MYOC gene, located at the GLC1A locus on chromosome 1q24.3-q25.2, has been confirmed to be associated with JOAG and POAG, although mutation frequencies vary between ethnic groups (20). The altered protein product secreted into the extracellular matrix 
of the trabecular meshwork causes a severe form of autosomal dominant JOAG associated with very high IOP (9). Although up to $20 \%$ of JOAG may be associated with MYOC mutations, mutations in this gene have been identified in only 3 to $5 \%$ of POAG patients $(7,21)$. Mutations in the OPTN gene, located at the GLC1E locus on chromosome 10p14-p15, result in normal tension glaucoma (NTG) without elevated IOP, a subtype of POAG (10).

To investigate the underlying genetic influences of primary glaucoma, molecular analysis of the MYOC and OPTN genes was performed in 112 Korean sporadic primary glaucoma patients, with the results compared to healthy controls.

\section{Patients and methods}

Patients. All 112 patients with primary glaucoma from unrelated Korean patients were recruited from the ophthalmology clinic of Seoul St. Mary's Hospital (Seoul, Korea), including 17 POAG, 19 JOAG and 76 NTG patients. Healthy, unrelated Korean individuals $(n=100)$ served as the non-selected population control. All patients and healthy controls in the study provided written informed consent for clinical and molecular analyses, and the study protocol was approved by the institutional review board of The Catholic University of Korea (Seoul, Korea). The diagnostic criteria of POAG were an IOP > $21 \mathrm{mmHg}$ by Goldmann applanation tonometry (GAT), presence of glaucomatous visual field defect or glaucomatous optic neuropathy and open angle. Where onset occurred at 5-35 years of age, patients were diagnosed with JOAG (22). The diagnostic criteria of NTG were an IOP $<22 \mathrm{mmHg}$ by GAT, presence of glaucomatous visual field defect or glaucomatous optic neuropathy and open angle. Patients with secondary glaucoma resulting from trauma, uveitis, neovascular or steroid-induced glaucoma (SIG), and other associated ocular or systemic anomalies were excluded from the present study. Healthy controls had IOP $<20 \mathrm{mmHg}$, a normal optic disc appearance without suspicious glaucomatous changes, and no family or personal history of primary glaucoma.

Molecular analysis of the MYOC and OPTN genes. Genomic DNA samples were extracted from the peripheral blood using the QIAamp DNA Mini kit (Qiagen GmbH, Hilden, Germany). Entire coding exons and flanking intronic sequences of $M Y O C$ and $O P T N$ were amplified by polymerase chain reaction (PCR) using different combinations of forward and reverse primers designed by the authors (Table I). Briefly, the PCR reaction had a total volume of $15 \mu \mathrm{l}$, comprising $10 \mu \mathrm{l} \mathrm{Taq}$ PCR Master Mix kit (Qiagen $\mathrm{GmbH}$ ) containing Taq DNA Polymerase, 2X Qiagen PCR Buffer, $3 \mathrm{mM} \mathrm{MgCl}_{2}$, and $400 \mu \mathrm{M}$ of each deoxynucleotide, $2 \mu \mathrm{l} 5 \mathrm{X}$ Q-Solution, $1 \mu \mathrm{l}$ primer mix, and $2 \mu \mathrm{l}$ genomic DNA (50 ng/ $\mu \mathrm{l})$. The PCR was amplified with a C1000 thermal cycler (Bio-Rad Laboratories, Inc., Hercules, CA, USA) under the following conditions: $5 \mathrm{~min}$ at $95^{\circ} \mathrm{C}$, followed by 35 cycles of $95^{\circ} \mathrm{C}$ for $30 \mathrm{sec}, 60^{\circ} \mathrm{C}$ for $30 \mathrm{sec}$ and $72^{\circ} \mathrm{C}$ for $1 \mathrm{~min}$, and a final step of $72^{\circ} \mathrm{C}$ for 5 min. Direct sequencing of PCR products was performed with the BigDye Terminator version 3.1 Cycle Sequencing kit (Applied Biosystems; Thermo Fisher Scientific, Inc., Waltham, MA, USA) and the products were resolved on ABI 3130XL Genetic Analyzer (Applied Biosystems; Thermo Fisher
Scientific, Inc.). The resulting sequence electropherogram was analyzed using Sequencher software version 4.9 (Gene Codes Corporation, Ann Arbor, MI, USA). Sequence data were analyzed using reference sequences in GenBank (www.ncbi. nlm.nih.gov/genbank/). The RefSeq IDs NM_000261.1 for MYOC and NM_001008211.1 for OPTN were used for cDNA nucleotide numbering. All identified variants were confirmed by bidirectional resequencing.

Genetic variations were contrasted with Human Gene Mutation Database Public (www.hgmd.cf.ac.uk), 1,000 genomes project browser (browser.1000genomes. org) and the single nucleotide polymorphism database (www.ncbi.nlm.nih.gov/projects/SNP). Mutation pathogenicity was predicted through PolyPhen-2 version 2.2.2 (genetics.bwh.harvard.edu/pph2) (23) and PROVEAN version 1.1 (provean.jcvi.org) (24), the first predictor that includes in-frame insertions/deletions. To assess the extent of conservation of a novel variant of MYOC and OPTN hypothesized to be associated with disease, the amino acid sequence was aligned with protein sequences of various mammalian species using Clustal Omega software (www. ebi.ac.uk/Tools/msa/clustalo/) (25).

Haplotype analysis of the MYOC and OPTN genes. Haplotypes of each gene were constructed based on the genotype data of the MYOC and OPTN variants obtained from the 112 patients and 100 healthy controls. Haplotype reconstruction and frequency estimation were performed using haplo. em, an implementation of an Expectation-Maximization algorithm included in the $\mathrm{R}$ package haplo.stats, which computes maximum likelihood estimates of haplotype probabilities from unphased genotypes measured on unrelated individuals ( $\mathrm{R}$ Foundation for Statistical Computing, Vienna, Austria; www.r-project.org). The frequencies of variant status between the patients and healthy controls were compared by $\chi^{2}$ or Fisher's exact test using MedCalc software version 12.7.2 (MedCalc Software bvba, Ostend, Belgium). $\mathrm{P}<0.05$ was considered to indicate a statistically significant difference.

\section{Results}

A total of three $M Y O C$ and four OPTN variants potentially associated with primary glaucoma were identified in 4 and 18 patients, respectively (Table II).

Molecular analysis of MYOC. Missense variants of MYOC were identified in two JOAG patients (P107 and P044) with a family history of primary glaucoma (pedigree analysis of P107 is presented in Fig. 1A). One was determined to be a novel missense variant, p.Leu255Pro, (P107; Fig. 1B) which was predicted to be 'probably damaging' with a score of 0.970 by PolyPhen-2 and was expected to be 'deleterious' with a score of -2.887 by PROVEAN. The position of changed amino acid was conserved among other mammalian species (Fig. 1C). No healthy control exhibited the same variant. The other variant identified, p.Thr353Ile, has previously been reported in Korean POAG (26). In addition, combined heterozygous variants $p .[$ Thr123=;Ile $288=$ ] were identified in 2 of $112(2 \%)$ patients but not in healthy controls; $p . T h r 123=[\mathrm{rs} 75682756$; 
Table I. Oligonucleotide primer sequences used for mutation analysis of $M Y O C$ and $O P T N$ genes.

\begin{tabular}{|c|c|c|c|c|}
\hline \multirow[b]{2}{*}{ Gene } & \multirow[b]{2}{*}{ Exon } & \multicolumn{2}{|c|}{ Primer sequence ( $5^{\prime}$ to $3^{\prime}$ ) } & \multirow[b]{2}{*}{ Size (bp) } \\
\hline & & Forward & Reverse & \\
\hline MYOC & $1 \mathrm{a}$ & TCTTGCTGGCAGCGTG & CTGGTCCAAGGTCAATTGGT & 626 \\
\hline MYOC & $1 b$ & AGCACCCAACGCTTAGACCT & TCTGTCTTGTGCTAGCTGTGC & 497 \\
\hline MYOC & 2 & TGCCACCACATCCAGCTAAT & CTCTGCTCCCAGGGAAGTTA & 495 \\
\hline MYOC & $3 a$ & ACCCAGACGATTTGTCTCCA & GCCTCATCGGTGCTGTAAAT & 586 \\
\hline MYOC & $3 b$ & CGCTGAGTCCAGAACTGTCA & CGCCCTCAGACTACAATTCC & 685 \\
\hline OPTN & 1 & CGGACAGCGAGGGTGGGTA & GCGGGTACCGTTTTCAGG & 445 \\
\hline OPTN & 2 & TCCACATGGATGCCTCTACA & TTCCCATGCAAATCTTCAAA & 459 \\
\hline OPTN & 3 & TGTTAGCCAGGATGGTCTCA & AGAGGTTGATGGGACATTGC & 391 \\
\hline OPTN & 4 & CACACACACACTTTTCTGAAGC & CCCCACCAGCTACCACCTAT & 497 \\
\hline OPTN & 5 & CTTCGTCTTTTTGCTGCTGA & CTTCCAAGACCAGGCAAAAC & 492 \\
\hline OPTN & 6 & TGTAAAGATGGGGGTCTTGC & GAAAATGAGAGCCAATTTATCTTTG & 491 \\
\hline OPTN & 7 & CTTGGGTTGCATGTCACAAA & CAGTGTGAGCCAAACAGGAA & 398 \\
\hline OPTN & 8 & GACCAGCTGTGCTTGTTCAC & CAGACAGTGAGTGCTGTTTGG & 495 \\
\hline OPTN & 9 & TTTCACTTGCCTTTTACCTCTG & GACACAGAGCAGGACAAGGA & 498 \\
\hline OPTN & 10 & TTGGGGTATTGTCAAAGTTGG & ATGCCCCTAAATGGCAGAAT & 486 \\
\hline OPTN & 11 & TCATAAACCCTACAGCCCTAAAA & TGCTAGGACTCCTTCAGATAAGTG & 398 \\
\hline OPTN & 12 & GCTAGTAGGTCGTGGGGTGA & GGAAAACAACCTTTGAAACCA & 346 \\
\hline OPTN & 13 & CCGGCCAGAGCTGATAAT & TTTTAATACACTCACGGGTGAAA & 394 \\
\hline OPTN & 14 & AGCAGGATTGTGCATCTGTG & GCGCGAACACAGCTATTCTT & 369 \\
\hline OPTN & 15 & GGTTTTTATGAACCTTGGCAGT & GATTCGGTGGGTAATGGATG & 381 \\
\hline OPTN & 16 & TGCATCGTGATGACTTCAGTT & СТСАAАСССТGACССCAAGT & 500 \\
\hline
\end{tabular}

Table II. Frequencies of $M Y O C$ and $O P T N$ variants identified in primary glaucoma.

Primary glaucoma, $\mathrm{n}=112$

POAG, JOAG, NTG, Healthy control,

\begin{tabular}{|c|c|c|c|c|c|c|}
\hline Gene & Variant & Zygosity & $\mathrm{n}=17$ & $\mathrm{n}=19$ & $\mathrm{n}=76$ & $n=10$ \\
\hline MYOC & c. $-83 \mathrm{G}>\mathrm{A}$ and c.764T $>$ C;p.Leu255Pro & Combined heterozygous & 0 & 1 & 0 & 0 \\
\hline MYOC & c.1058C >T;p.Thr353Ile & Heterozygous & 0 & 1 & 0 & 0 \\
\hline MYOC & c. $369 \mathrm{C}>\mathrm{T} ; p$. Thr123= and c. $864 \mathrm{C}>\mathrm{T} ; p$. Ile $288=$ & Combined heterozygous & 0 & 1 & 1 & \\
\hline OPTN & c. $102 \mathrm{G}>\mathrm{A} ;$ p.Thr34= & Homozygous & 1 & 1 & 2 & \\
\hline OPTN & c.293T>A;p.Met98Lys & Homozygous & 1 & 1 & 2 & \\
\hline OPTN & c.811C >T;p.Arg271Cys & Heterozygous & 0 & 0 & 1 & \\
\hline OPTN & c.102G $>\mathrm{A} ; p . T h r 34=$ and c.1634G $>\mathrm{A} ; p . A r g 545 G \ln$ & Combined heterozygous & 2 & 2 & 5 & \\
\hline
\end{tabular}

JOAG, juvenile open-angle glaucoma; POAG, primary open-angle glaucoma; NTG, normal tension glaucoma; MYOC, myocilin; OPTN, optineurin.

minor allele frequency (MAF)/minor allele count (MAC) by 1000 Genomes $=0.0014 / 7]$, p.Ile $288=(\mathrm{rs} 181923440$; $\mathrm{MAF} / \mathrm{MAC}=0.0010 / 5)$. The $M Y O C$ promoter variant c. $-83 \mathrm{G}>\mathrm{A}$ (rs2075648; MAF/MAC=0.1380/691) was detected only as a heterozygous state in a JOAG patient with p.Leu255Pro and in five NTG patients, but not in the 100 healthy controls (Table III). Clinical manifestations of primary glaucoma with $M Y O C$ are summarized in Table IV.
Molecular analysis of OPTN. OPTN variants were identified in 18 patients with primary glaucoma. One patient (P086) harbored a novel variant, $p . A r g 271 C y s$ as a heterozygous state (Fig. 2A). This variant was predicted to be 'benign' with a score of 0.047 by PolyPhen-2 and was expected to be 'neutral' with a score of -1.726 by PROVEAN. This protein sequence was not highly conserved across the compared species, and the sequence in chicken had a cysteine in that position (Fig. 2B). 


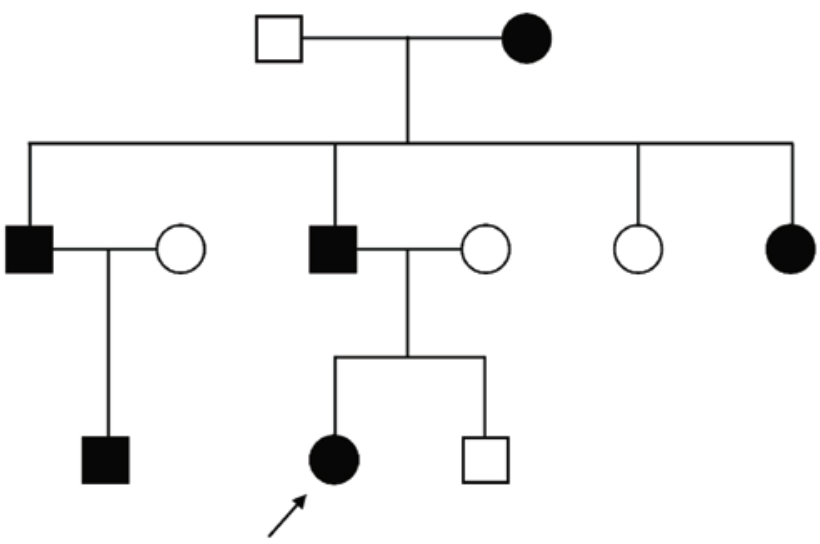

B

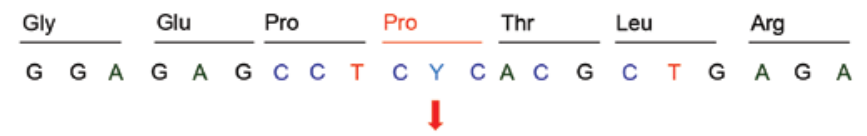

\begin{tabular}{|c|c|}
\hline MYOC_human & EGDTGCGELVWVGEPLTLRTAETITGKYGVWM \\
\hline MYOC_chimpanzee & EGDTGCGELVWVGEPLETLRTAETITGKYGVWM \\
\hline MYOC_orangutan & EGDNGCGELVWVGEPLTLRTAETITGKYGVWM \\
\hline MYOC_macaque & EGDNGCGELVWVGEPLTLRTAETITGKYGVWM \\
\hline MYOC_horse & EGDNGCGELVWVGEPLTLRTAETITGKYGVWM \\
\hline MYOC_dog & EGDSGCGELVWVGEPLTLRTAETITGKYGVWM \\
\hline MYOC_cow & EGGTGCGELVMVGEPITLRTAETITGKYGVWM \\
\hline MYOC_opossum & DVGDGCGELVWVGEPIALRKAETIAGKYGVWM \\
\hline MYOC_mouse & EGDKGCGALVMVGEPVTLRTAETIAGKYGVWM \\
\hline MYOC_rat & EGDKGCGVLMWVGEPV̄TLRTAETITGKYGVWM \\
\hline MYOC_chicken & DSGTGCGLAWVGEPVVLGRADTIAGKYGVWM \\
\hline MYOC_zebrafish & ADISGDLVWVENPËVHRKADSIAGKYGVWM \\
\hline
\end{tabular}

Figure 1. (A)Pedigree analysis of patient P107 diagnosed with juvenile open-angle glaucoma, with a novel missense variant $p$.Leu255Pro. Proband (indicated by the arrow) and affected family members revealed the same mutation in the heterozygous state. (B) Partial sequence of exon3 of $M Y O C$ revealed a heterozygous single-base substitution (c.764T>C) leading to missense variant p.Leu255Pro in patient P107. (C) Alignment of MYOC amino acid sequences in human and other species. The position of the changed amino acid in the patient with glaucoma identified in the present study is underlined. The conservation of p.Leu255Pro was assumed by protein alignment of various MYOC orthologs using Clustal Omega software. MYOC, myocilin.

One novel synonymous variant, p.Leu568=; c.1704A>G was identified in heterozygosity. These two variants were not detected in healthy controls.

In addition, three reported variants associated with primary glaucoma $(10,27)$, including $p . T h r 34=(\mathrm{rs} 2234968)$, p.Met98Lys (rs11258194) and p.Arg545Gln (rs75654767) were identified (Table V). The p.Thr34=,p.Met98Lys and p.Arg545Gln mutations were detected in 40 (36\%), 19 (17\%), and $10(9 \%)$ patients with primary glaucoma as well as in 25 (25\%), $18(18 \%)$, and 2 (2\%) healthy controls, respectively, in a heterozygous or homozygous state. The odds ratio (OR) was not statistically different for $p . T h r 34=$ and p.Met 98 Lys by the $\chi^{2}$ test $(\mathrm{P}=0.061$ and $\mathrm{P}=0.492$, respectively); however, it was significant for p.Arg545Gln by Fisher's exact test $[\mathrm{OR}=4.804,95 \%$ confidence interval $(\mathrm{CI})=1.026-22.482$; relative risk $=1.634,95 \% \mathrm{CI}=1.226-2.178 ; \mathrm{P}=0.037]$. The presence of one of homozygous $p \cdot[$ Thr34=;Thr34=] (4/112; 4\%), homozygous p.[Met98Lys;Met98Lys] (4/112; 4\%) or combined heterozygous $p .[T h r 34=; A r g 545 G \ln ](9 / 112,8 \%)$ was significantly associated with the development of primary glaucoma
$(\mathrm{OR}=8.768,95 \% \mathrm{CI}=1.972-38.988$; relative risk $=1.818,95 \%$ $\mathrm{CI}=1.473-2.244 ; \mathrm{P}=0.001)$. Clinical manifestations of primary glaucoma with $O P T N$ variants are summarized in Table VI.

\section{Discussion}

The present study reports a molecular analysis of $M Y O C$ and OPTN genes in 112 patients with primary glaucoma. One novel MYOC variant, p.Leu255Pro, in patient P107 with a family history of glaucoma was predicted to have a deleterious effect by in silico analysis. This variant is a possible pathogenic mutation associated with the development of primary glaucoma. The second MYOC variant, p.Thr353Ile, in patient P044 with a family history of glaucoma has been previously reported as a pathologic mutation for POAG and resides in the olfactomedin-homology region. It may be involved in the regulation of IOP in trabecular-meshwork cells (26). The presence of heterozygous $p . T h r 123=$ and $p . I l e 288=$ was observed only in patients with JOAG and NTG. Thus, $p .[$ Thr123=;Ile288=] may be a part of the haplotype variant associated with the 

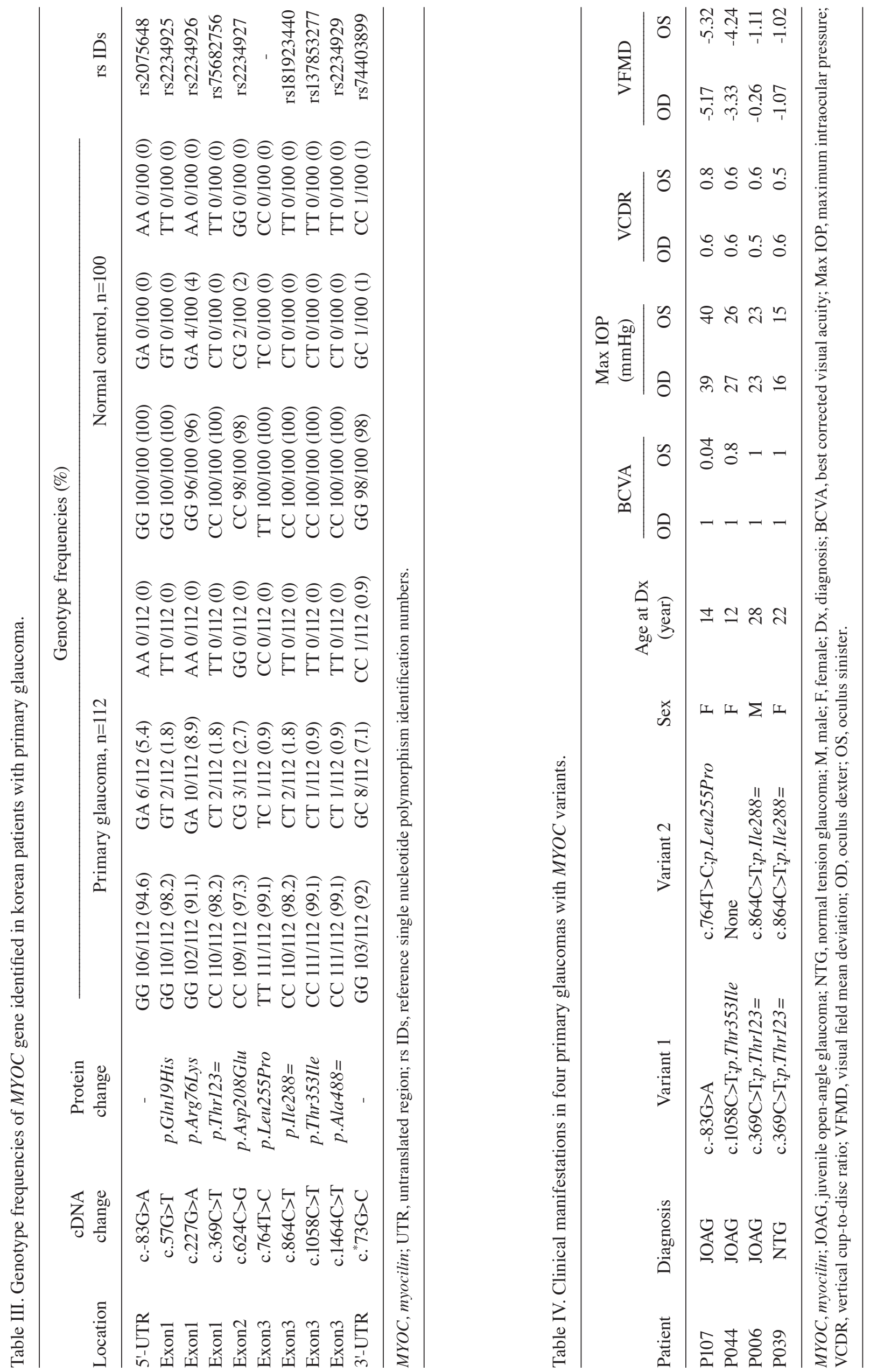


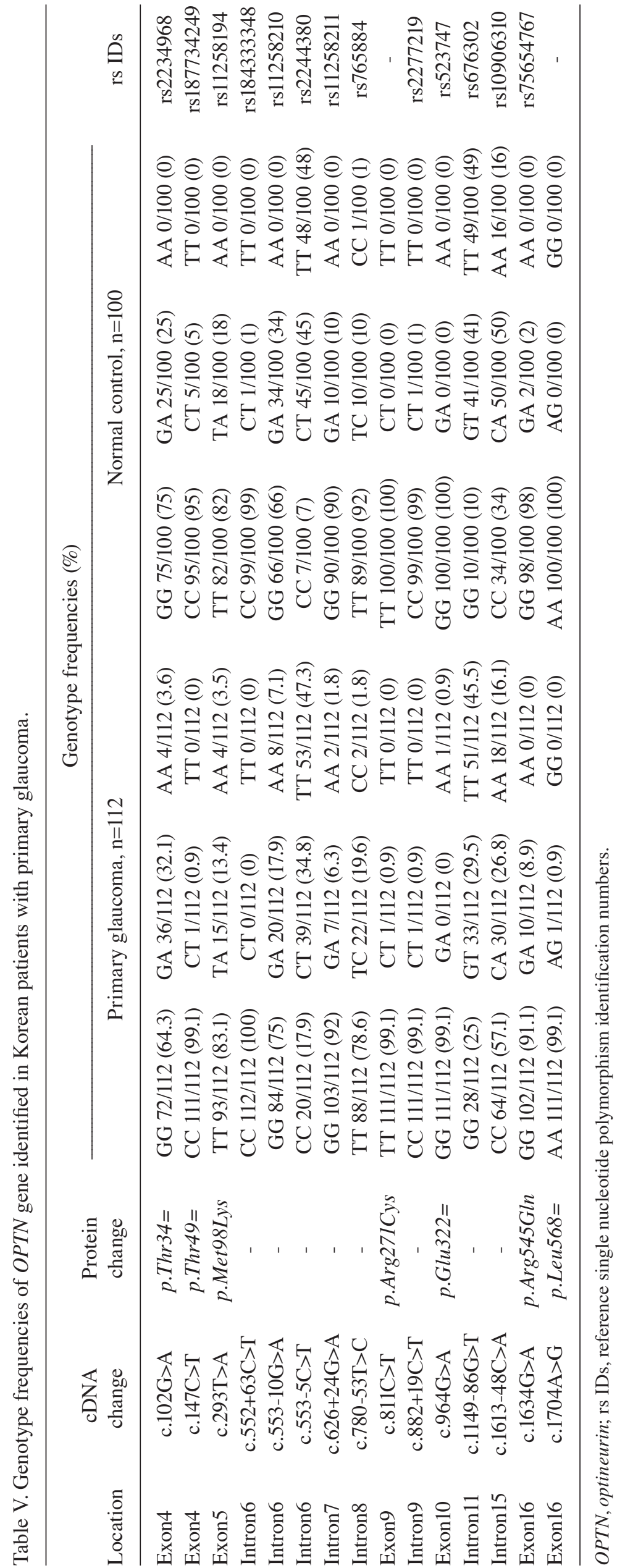




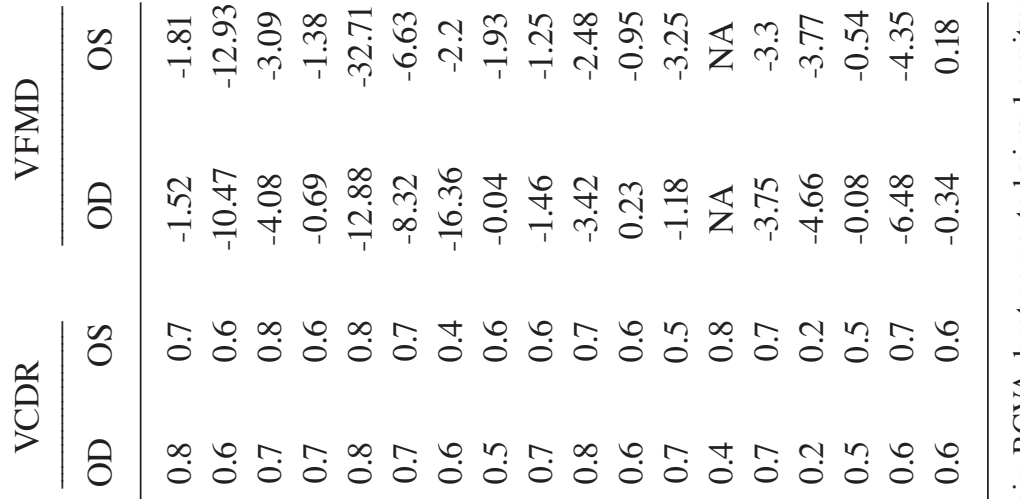

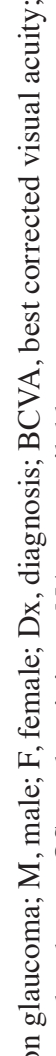

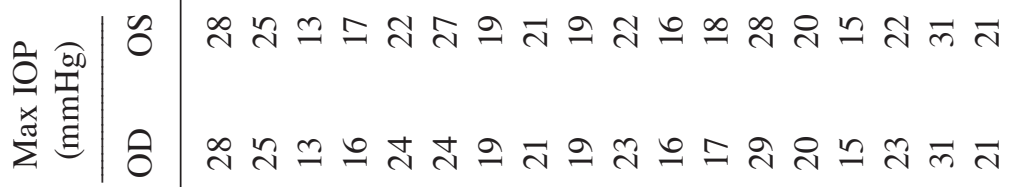

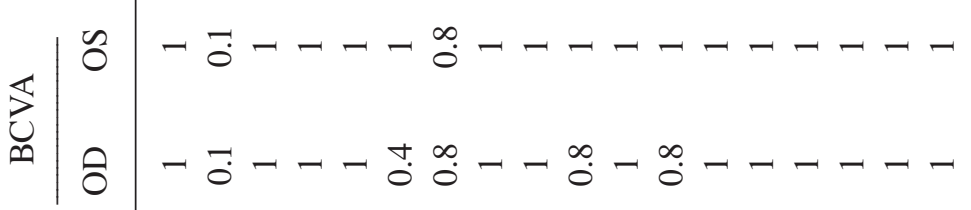

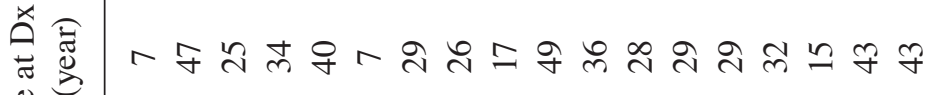
$\mathbb{8}_{<}$

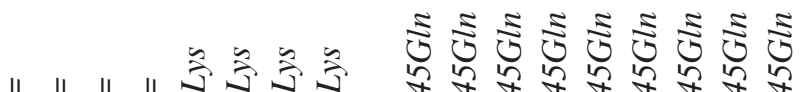

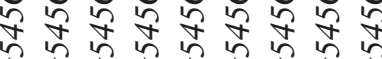

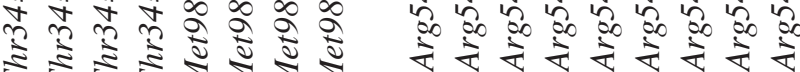
है है

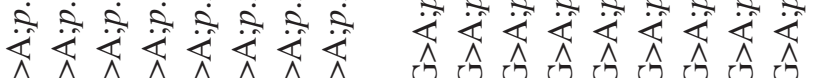

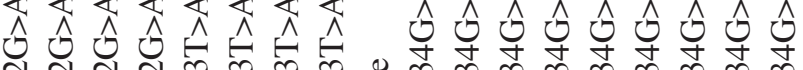

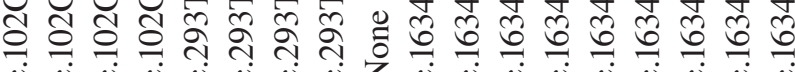

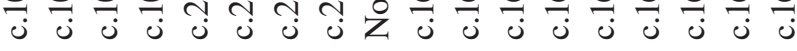

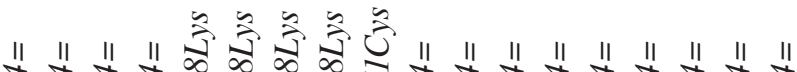

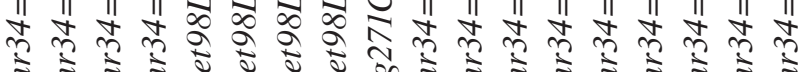

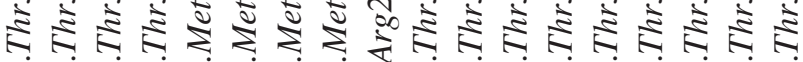

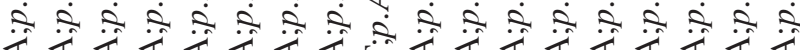

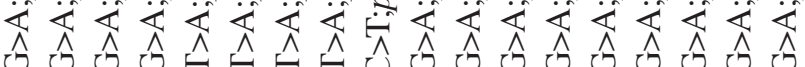

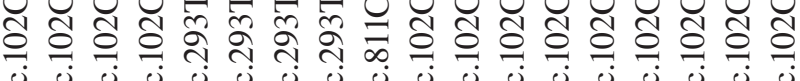

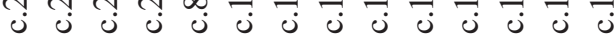

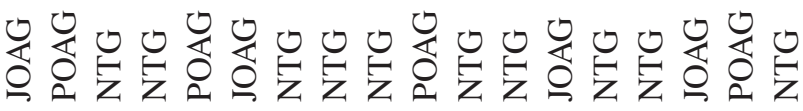
0
0
0 党

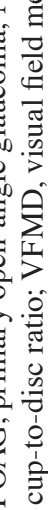


A

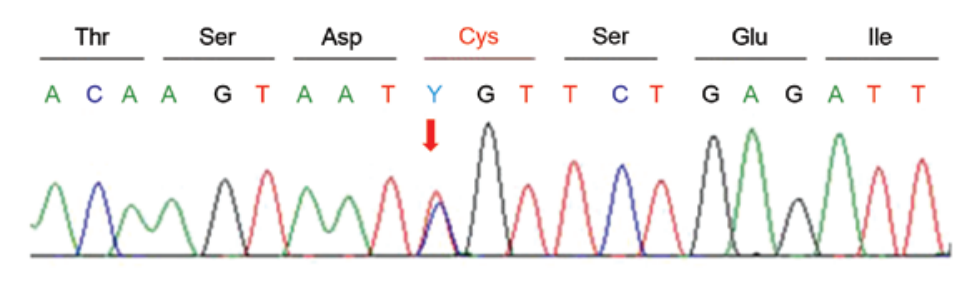

B

\begin{tabular}{ll}
\hline OPTN_human & EAKERVSDFEKKTSNRSEIETQTEGSTEKEN \\
OPTN_chimpanzee & EAKERVSDFEKKTSNRSEIETQTEGSTEKEN \\
OPTN_orangutan & EAKERVSDFEKKASNRSEIETQTEGSTEKEN \\
OPTN_macaque & EAKERVSDFEKKASNRSEIETQTEGSTEKEN \\
OPTN_horse & EAKERISYFEKKVNYRSEIETQTEESKEKEK \\
OPTN_dog & EAKERVLYFEKKASGGSEIETQTEESTEKEK \\
OPTN_cow & EAKERISDFEKKAKDHSETETQTEEHTEQEK \\
OPTN_opossum & AAKDKLSDLEKKAEDHSENATQTEEGPGEEK \\
OPTN_mouse & EAKERISDFEKKANGESSTEKQTARRADRE- \\
OPTN_rat & EAKERISDFEKKANGHSAIETQTEGSTQKE- \\
OPTN_chicken & DHKERLSKMENETSNCLLESGTQT-------N \\
OPTN_zebrafish & EARGRIAELESKLEH_ADSSAQTSLPS----- \\
\hline
\end{tabular}

Figure 2. (A) Partial sequence of exon9 of $O P T N$ revealed a heterozygous single-base substitution (c.811C $>$ T) leading to missense variant $p . A r g 271 C y s$ in patient P086 with normal tension glaucoma. (B) Alignment of OPTN amino acid sequences in human and other mammalian species. The position of the changed amino acid in the patient with glaucoma identified in the present study is underlined. The conservation of $p$.Arg271Cys was assessed by protein alignment of various OPTN orthologs using Clustal Omega. OPTN, optineurin.

development of primary glaucoma. Further extended haplotype analysis is required to confirm the association of $M Y O C$ haplotype variants. The variant in the 5'-UTR region, c.-83G $>A$, which was initially reported in Western countries $(20,28)$, and subsequently observed in Hong Kong (29) and the Philippines (30), was identified only in primary glaucoma patients in the present study. The association of c.- $83 \mathrm{G}>\mathrm{A}$ and the risk of primary glaucoma remains controversial due to the variable frequency and the non-significant differences between POAG patients and controls observed in previous studies $(28,31,32)$.

Genetic analysis of the $O P T N$ coding region was performed in all patients with primary glaucoma. Notably, $O P T N$ variants (10/76, 13.2\%) were identified more frequently than MYOC variants $(1 / 76,1.3 \%)$ in NTG patients, which is consistent with previous studies $(33,34)$. The three $O P T N$ variants $p . T h r 34=$, p.Leu $40=$ and p.Glu89His were identified in 7 of 53 Korean NTG patients (33), whereas only one patient with the MYOC variant $p . L e u 411=$ was reported from 32 separate Korean NTG patients (34). Supporting the findings of the present study, Rezaie et al (10) suggested that mutations in OPTN may be responsible for $16.7 \%$ of the hereditary forms of NTG and that there is an additional risk factor of $13.6 \%$ in familial and sporadic cases. Furthermore, Sohn et al (35) demonstrated that the $M Y O C$ gene itself was not associated with OAG, including POAG, NTG and SIG. Their results do not support the hypothesis that MYOC induction may be linked to IOP variation and that promoter variants of MYOC may be a risk factor for the pathogenesis of OAG.

A novel $O P T N$ variant, $p$.Arg271Cys, of unknown significance was identified in patient P086 with NTG $(1 / 112,1 \%)$. This variant led to replacement of arginine with cysteine at codon 271 , however, the protein sequence was not highly conserved across species. Although this variant was predicted to be 'benign' or 'neutral', it is potentially pathogenic as it was not present in the healthy controls. Segregation analysis and/or functional studies are required to verify the pathogenicity or neutrality of this variant.

Of the OPTN haplotype variants, $p . T h r 34=, p$. Met 98 Lys and p.Arg $545 \mathrm{Gln}$ have been previously reported as possible glaucoma-causing mutations $(10,27)$. However, they were present at reduced frequencies as a heterozygous state in healthy controls.

The $p . T h r 34=$ variant was detected in 40 of $112(36 \%)$ patients with primary glaucoma and in 25 of $100(25 \%)$ healthy controls in a heterozygous or homozygous state in the present study. Homozygosity for $p . T h r 34=$ was observed only in four patients with primary glaucoma (P059, P060, P098 and P109). Funayama et al (27) reported that p.Thr34= was weakly associated with patients with OAG with elevated IOP, whereas p.Met98Lys was weakly associated with patients with OAG with normal IOP. In interaction analysis between olfactomedin 2 (OLFM2) and $O P T N$ genes in patients with $\mathrm{OAG}$, the c.317G $>\mathrm{A}$; p.Arg106Gln of OLFM2 and c. $412 \mathrm{G}>\mathrm{A}$; p.Thr $34=$ of $O P T N$ and the c.1281C $>$ T; p.Arg 427Arg of OLFM2 and c.412G $>\mathrm{A}$; p.Thr34 = of $O P T N$ were significantly associated with OAG with elevated IOP. These results suggest that these variants in $O L F M 2$ and $O P T N$ contribute interactively to $\mathrm{OAG}$, indicating a polygenic etiology with different properties for $p \cdot T h r 34=$ and p.Met98Lys variants of $O P T N$.

The p.Met98Lys variant was identified in 19 of $112(17 \%)$ patients with primary glaucoma as well as in 18 of $100(18 \%)$ healthy controls as a heterozygous or homozygous state in the present study. Alward et al (36) and Fuse et al (37) reported a significant association between p.Met98Lys and glaucoma in Japanese patients. By contrast, Toda et al (38) identified similar frequencies of p.Met98Lys in Japanese glaucoma patients and controls. Notably, p.Met 98 Lys has been demonstrated to be a polymorphic variant in German, French and Moroccan patients $(39,40)$. By contrast to previous studies $(10,41,42)$, the 
frequency difference in the present study (4 vs. 0\%) between the patients with homozygous p.Met98Lys (P014, P029, P054 and P058) and healthy controls was highly significant. p.Met98Lys is located within a putative basic leucine zipper domain and is conserved in macaques; it may represent a risk associated factor or a dominant susceptibility allele (10). Wild-type OPTN protein, operating through the tumor necrosis factor $\alpha$ pathway, may have a neuroprotective role in the eye and optic nerve; however when defective, it produces visual loss and optic neuropathy as typically observed in normal and high-pressure glaucoma (10).

The $p . A r g 545 G l n$ variant was reported previously in POAG families with normal IOP (10). Although the p.Arg545Gln variant is not part of a known protein domain, it is situated near the only zinc finger motif within OPTN. This motif is typically observed in transcription factors. p.Arg545Gln has been detected in similar frequencies in Japanese glaucoma patients and healthy controls (38). Alward et al (36) suggested that $p . A r g 545 G l n$ may not be a disease-causing polymorphism. Results concerning the effect of $O P T N$ on glaucoma have been equivocal $(10,32,43,44)$; however, the expression of $M Y O C$ may be regulated by $O P T N$ (45). Notably, results from the present study support the view that the three variants of OPTN may be involved in the development of primary glaucoma, as the OR for the haplotype harboring homozygous $p . T h r 34=$ or $p$. Met 98 Lys as well as a simultaneous presence of heterozygous $p . T h r 34=$ and p.Arg545Gln was statistically significant by the Fisher's exact test $(\mathrm{OR}=8.768,95 \%, \mathrm{CI}=1.972-38.988$; relative risk $=1.818$, 95\% CI=1.473-2.244; $\mathrm{P}=0.001$ ).

In conclusion, haplotype variants identified in the present study may be regarded as potential contributing factors for primary glaucoma in Korea. The present study provides insight into the genetic or haplotype variants contributing to primary glaucoma. Further studies, including on additional genes, are required to elucidate the underlying pathogenic mechanism using larger cohorts to provide additional statistical power.

\section{Acknowledgements}

The authors would like to thank The Catholic Genetic Laboratory Center (Seoul, Korea) for its assistance in conducting the present study and compiling this report. The present study was supported by a grant from the Basic Science Research Program through the National Research Foundation of Korea (Daejeon, Korea; grant no. NRF-2013R1A1A2006801) funded by the Ministry of Education (Sejong, Korea).

\section{References}

1. Foster PJ, Buhrmann R, Quigley HA and Johnson GJ: The definition and classification of glaucoma in prevalence surveys. Br J Ophthalmol 86: 238-242, 2002.

2. Pakravan M, Yazdani S, Javadi MA, Amini H, Behroozi Z, Ziaei H, Katibeh M, Solaimanizad R, Ghahari E and Yaseri M: A population-based survey of the prevalence and types of glaucoma in central Iran: The Yazd eye study. Ophthalmology 120: 1977-1984, 2013.

3. Casson RJ, Chidlow G, Wood JP, Crowston JG and Goldberg I: Definition of glaucoma: Clinical and experimental concepts. Clin Experiment Ophthalmol 40: 341-349, 2012.

4. Weinreb RN, Aung T and Medeiros FA: The pathophysiology and treatment of glaucoma: A review. JAMA 311: 1901-1911, 2014.
5. Goldwyn R, Waltman SR and Becker B: Primary open-angle glaucoma in adolescents and young adults. Arch Ophthalmol 84: 579-582, 1970.

6. Booth A, Churchill A, Anwar R, Menage M and Markham A: The genetics of primary open angle glaucoma. $\mathrm{Br} \mathrm{J}$ Ophthalmol 81: 409-414, 1997.

7. Wiggs JL: Genetic etiologies of glaucoma. Arch Ophthalmol 125: 30-37, 2007.

8. Khan AO: Genetics of primary glaucoma. Curr Opin Ophthalmol 22: 347-355, 2011.

9. Stone EM, Fingert JH, Alward WL, Nguyen TD, Polansky JR, Sunden SL, Nishimura D, Clark AF, Nystuen A, Nichols BE, et al: Identification of a gene that causes primary open angle glaucoma. Science 275: 668-670, 1997.

10. Rezaie T, Child A, Hitchings R, Brice G, Miller L, Coca-Prados M, Héon E, Krupin T, Ritch R, Kreutzer D, et al: Adult-onset primary open-angle glaucoma caused by mutations in optineurin. Science 295: 1077-1079, 2002.

11. Monemi S, Spaeth G, DaSilva A, Popinchalk S, Ilitchev E, Liebmann J, Ritch R, Héon E, Crick RP, Child A and Sarfarazi M: Identification of a novel adult-onset primary open-angle glaucoma (POAG) gene on 5q22.1. Hum Mol Genet 14: 725-733, 2005

12. Footz TK, Johnson JL, Dubois S, Boivin N, Raymond V and Walter MA: Glaucoma-associated WDR36 variants encode functional defects in a yeast model system. Hum Mol Genet 18: 1276-1287, 2009.

13. Pasutto F, Matsumoto T, Mardin CY, Sticht H, Brandstätter JH, Michels-Rautenstrauss K, Weisschuh N, Gramer E, Ramdas WD, van Koolwijk LM, et al: Heterozygous NTF4 mutations impairing neurotrophin-4 signaling in patients with primary open-angle glaucoma. Am J Hum Genet 85: 447-456, 2009.

14. Aung T, Ocaka L, Ebenezer ND, Morris AG, Krawczak M, Thiselton DL, Alexander C, Votruba M, Brice G, Child AH, et al: A major marker for normal tension glaucoma: Association with polymorphisms in the OPA1 gene. Hum Genet 110: 52-56, 2002.

15. Guo Y, Chen X, Zhang H, Li N, Yang X, Cheng W and Zhao K: Association of OPA1 polymorphisms with NTG and HTG: A meta-analysis. PLoS One 7: e42387, 2012.

16. Kaur K, Mandal AK and Chakrabarti S: Primary congenital glaucoma and the involvement of CYP1B1. Middle East Afr J Ophthalmol 18: 7-16, 2011

17. Jelodari-Mamaghani S, Haji-Seyed-Javadi R, Suri F, Nilforushan N, Yazdani S, Kamyab K and Elahi E: Contribution of the latent transforming growth factor- $\beta$ binding protein 2 gene to etiology of primary open angle glaucoma and pseudoexfoliation syndrome. Mol Vis 19: 333-347, 2013.

18. Fingert J: Primary open-angle glaucoma genes. Eye (Lond) 25: 587-595, 2011.

19. Shastry BS: Genetic susceptibility to primary angle closure glaucoma (PACG). Discov Med 15: 17-22, 2013.

20. Fingert JH, Héon E, Liebmann JM, Yamamoto T, Craig JE, Rait J, Kawase K, Hoh ST, Buys YM, Dickinson J, et al: Analysis of myocilin mutations in 1703 glaucoma patients from five different populations. Hum Mol Genet 8: 899-905, 1999.

21. Menaa F, Braghini CA, Vasconcellos JP, Menaa B, Costa VP, Figueiredo ES and Melo MB: Keeping an eye on myocilin: A complex molecule associated with primary open-angle glaucoma susceptibility. Molecules 16: 5402-5421, 2011.

22. Turalba AV and Chen TC: Clinical and genetic characteristics of primary juvenile-onset open-angle glaucoma (JOAG). Semin Ophthalmol 23: 19-25, 2008.

23. Adzhubei IA, Schmidt S, Peshkin L, Ramensky VE, Gerasimova A, Bork P, Kondrashov AS and Sunyaev SR: A method and server for predicting damaging missense mutations. Nat Methods 7: 248-249, 2010.

24. Choi Y, Sims GE, Murphy S, Miller JR and Chan AP: Predicting the functional effect of amino acid substitutions and indels. PLoS One 7: e46688, 2012.

25. Sievers F, Wilm A, Dineen D, Gibson TJ, Karplus K, Li W, Lopez R, McWilliam H, Remmert M, Söding J, et al: Fast, scalable generation of high-quality protein multiple sequence alignments using Clustal Omega. Mol Syst Biol 7: 539, 2011.

26. Yoon SJ, Kim HS, Moon JI, Lim JM and Joo CK: Mutations of the TIGR/MYOC gene in primary open-angle glaucoma in Korea. Am J Hum Genet 64: 1775-1778, 1999. 
27. Funayama T, Mashima Y, Ohtake Y, Ishikawa K, Fuse N, Yasuda N, Fukuchi T, Murakami A, Hotta Y and Shimada N; Glaucoma Gene Research Group: SNPs and interaction analyses of noelin 2, myocilin, and optineurin genes in Japanese patients with open-angle glaucoma. Invest Ophthalmol Vis Sci 47: 5368-5375, 2006.

28. Alward WL, Fingert JH, Coote MA, Johnson AT, Lerner SF, Junqua D, Durcan FJ, McCartney PJ, Mackey DA, Sheffield VC and Stone EM: Clinical features associated with mutations in the chromosome 1 open-angle glaucoma gene (GLC1A). N Engl J Med 338: 1022-1027, 1998

29. Fan BJ, Leung YF, Pang CP, Baum L, Tam OS, Wang N and Lam SC: Single nucleotide polymorphisms of the myocilin gene in primary open-angle glaucoma patients. Zhonghua Yi Xue Yi Chuan Xue Za Zhi 21: 70-73, 2004.

30. Wang DY, Fan BJ, Canlas O, Tam PO, Ritch R, Lam DS, Fan DS and Pang CP: Absence of myocilin and optineurin mutations in a large Philippine family with juvenile onset primary open angle glaucoma. Mol Vis 10: 851-856, 2004.

31. Mukhopadhyay A, Acharya M, Mukherjee S, Ray J, Choudhury S, Khan M and Ray K: Mutations in MYOC gene of Indian primary open angle glaucoma patients. Mol Vis 8: 442-448, 2002.

32. Kumar A, Basavaraj MG, Gupta SK, Qamar I, Ali AM, Bajaj V, Ramesh TK, Prakash DR, Shetty JS and Dorairaj SK: Role of CYP1B1, MYOC, OPTN, and OPTC genes in adult-onset primary open-angle glaucoma: Predominance of CYP1B1 mutations in Indian patients. Mol Vis 13: 667-676, 2007.

33. Jeong DH, Kim MR, Mun YK and Kee C: OPTN gene mutation in normal-tension glaucoma. J Korean Ophthalmol Soc 44: 1903-1907, 2003.

34. Lee SJ, Hur WH and Kee C: Analysis of TIGR gene mutation in glaucoma. J Korean Ophthalmol Soc 41: 1095-1101, 2000.

35. Sohn S, Hur W, Choi YR, Chung YS, Ki CS and Kee C: Little evidence for association of the glaucoma gene MYOC with open-angle glaucoma. Br J Ophthalmol 94: 639-642, 2010.

36. Alward WL, Kwon YH, Kawase K, Craig JE, Hayreh SS, Johnson AT, Khanna CL, Yamamoto T, Mackey DA, Roos BR, et al: Evaluation of optineurin sequence variations in 1,048 patients with open-angle glaucoma. Am J Ophthalmol 136: 904-910, 2003.
37. Fuse N, Takahashi K, Akiyama H, Nakazawa T, Seimiya M, Kuwahara S and Tamai M: Molecular genetic analysis of optineurin gene for primary open-angle and normal tension glaucoma in the Japanese population. J Glaucoma 13: 299-303, 2004.

38. Toda Y, Tang S, Kashiwagi K, Mabuchi F, Iijima H, Tsukahara S and Yamagata Z: Mutations in the optineurin gene in Japanese patients with primary open-angle glaucoma and normal tension glaucoma. Am J Med Genet A 125A: 1-4, 2004.

39. Melki R, Belmouden A, Akhayat O, Brézin A and Garchon HJ: The M98K variant of the OPTINEURIN (OPTN) gene modifies initial intraocular pressure in patients with primary open angle glaucoma. J Med Genet 40: 842-844, 2003.

40. Weisschuh N, Neumann D, Wolf C, Wissinger B and Gramer E: Prevalence of myocilin and optineurin sequence variants in German normal tension glaucoma patients. Mol Vis 11: 284-287, 2005.

41. Mukhopadhyay A, Komatireddy S, Acharya M, Bhattacharjee A, Mandal AK, Thakur SK, Chandrasekhar G, Banerjee A, Thomas R, Chakrabarti S and Ray K: Evaluation of Optineurin as a candidate gene in Indian patients with primary open angle glaucoma. Mol Vis 11: 792-797, 2005.

42. Sripriya S, Nirmaladevi J, George R, Hemamalini A, Baskaran M, Prema R, Ve Ramesh S, Karthiyayini T, Amali J, Job $\mathrm{S}$, et al: OPTN gene: Profile of patients with glaucoma from India. Mol Vis 12: 816-820, 2006.

43. Tektas OY and Lütjen-Drecoll E: Structural changes of the trabecular meshwork in different kinds of glaucoma. Exp Eye Res 88: 769-775, 2009.

44. Cheng JW, Cheng SW, Ma XY, Cai JP, Li Y and Wei RL: The prevalence of primary glaucoma in mainland China: A systematic review and meta-analysis. J Glaucoma 22: 301-306, 2013.

45. Huang X, Li M, Guo X, Li S, Xiao X, Jia X, Liu X and Zhang Q: Mutation analysis of seven known glaucoma-associated genes in Chinese patients with glaucoma. Invest Ophthalmol Vis Sci 55: 3594-3602, 2014 